5. Леднёв В.С. Содержание образования: сущность, структура, перспективы. 2-е перераб. изд. М.: Высшая школа, 1991. 223 с.

6. Маркова А.К. Психология профессионализма. М.: Международный гуманитарный фонд «Знание», 1996. 312 c.

7. Митина Л.М. Психология труда и профессионального развития учителя. М.: Академия, 2004. 320 с.

8. Зеер Э.Ф. Психология профессий: учебное пособие для студентов вузов. 2-е изд., перераб., доп. М.: Академический Проект; Екатеринбург: Деловая книга, 2003. $336 \mathrm{c.}$

9. Байденко В.И. Компетенции в профессиональном образовании (к освоению компетентностного подхода) // Высшее образование в России. 2004. № 11. С. 3-13.

10. Лэнгле А. Эмоциональное выгорание с точки зрения экзистенциального анализа // Вопросы психологии. 2008. № 2. С. 3-16.

11. Рубинштейн С.Л. Бытие и сознание. Человек и мир. СПб.: Питер, 2003. 512 с.

12. Брушлинский А.А. Психология субъекта. М.: Институт психологии РАН, СПб.: Алетейя, 2003. 272 c.

13. Абульханова К.А. Психология и сознание личности. М., Воронеж, 1999. 224 с.
14. Знаков В.В. Психология субъекта как методология понимания человеческого бытия. Психологический журнал. 2003. Т. 24, № 2. С. 95-106.

15. Анциферова Л.И. Психология формирования и развития личности // Психология личности в трудах отечественных психологов. СПб., 2001.

16. Полунина О.В. Взаимосвязь увлеченности работой и профессионального выгорания (на примере представителей сферы обслуживания): дис. ... канд. псих. наук. М., 2009. 213 с.

17. Шоган Е.В. Экзистенциальные диалоги как фактор ценностно-смыслового развития личности старшеклассника в образовательном пространстве школы: дис. ... канд. псих. наук. Ростов-на-Дону, 2006. $230 \mathrm{c}$.

18. Мухина В.С. Возрастная психология. Феноменология развития: учебник для студ. высш. учеб. заведений. 10-е изд., перераб. и доп. М.: Академия, 2006. 608 c

19. Турусова О.В. Психология в вопросах, задачах и упражнениях: учебное пособие. Самара: Издательство Самарского университета, 1994. 406 с.

20. Тарасова С.А. Психология сотрудников УИС: личность, общение, деятельность: учебное пособие. Самара: Самарский юридический институт ФСИН России, 2007. 114 с.

\title{
DEVELOPMENT OF EXISTENTIAL ASPECTS OF PROFESSIONAL COMPETENCE OF PENITENTIARY SYSTEM PROSPECTIVE EMPLOYEES
}

(C) 2017

Tarasova Svetlana Alexandrovna, candidate of psychological sciences, associate professor of Penitentiary Psychology and Pedagogy Department Samara Law Institute of the Federal Penitentiary Service of Russia (Samara, Russian Federation)

Abstract. The paper discusses the problem of professional competence of penitentiary system employees. The author says that employees of the penal system should be ready for the challenges of the vital and professional way. The author defines existential aspect as part of holistic professional competence. Existential setting is included in the existential aspect of professional competence. Existential setting is defined as readiness of a future specialist for selfdevelopment and self-improvement. Existential setting is a spiritual resource of a person. Existential setting helps to maintain interest in the professional activity of penitentiary system employee in difficult situations. Existential setting is formed in the process of reflection development. The paper considers forms of educational work: existential dialogue, essays, solution of situational problems. The author gives a brief description of these forms of work and specific examples. The paper contains indicators of effectiveness: students' interest in the spiritual side of life as well as in problems of the meaning of life and professional activities.

Keywords: professional competence; professional activities; existential aspects of competence; penal system; existential attitude; subject; reflection; professional engagement; existential dialogue; essay; situational problems; existential resources; difficult life situations; forms of educational work.

УДК 378

\section{МЕЖДИСЦИПЛИНАРНАЯ ИНТЕГРАЦИЯ КАК МЕТОД ОБЕСПЕЧЕНИЯ ВЫСОКОЙ ИНТЕНСИВНОСТИ ОБУЧЕНИЯ ОДАРЕННЫХ ОБУЧАЮЩИХСЯ} (C) 2017

\author{
Тимощук Нина Александровна, кандидат филологических наук, доцент, \\ заведующий кафедрой психологии и педагогики \\ Михелькевич Валентин Николаевич, доктор технических наук, \\ профессор кафедры психологии и педагогики \\ Рябинова Елена Николаевна, доктор педагогических наук, \\ профессор кафедры высшей математики и прикладной информатики \\ Самарский государственный технический университет (2. Самара, Российская Федеращия)
}

Аннотация. В статье показано, что наряду с акцентированием значимости приоритета привлечения твор-
чески одаренной молодежи к научно-исследовательской деятельности в направлениях работы государствен-
ных и губернских структур Самарской области, в региональной Единой системе мер по выявлению и разви- 
Тимощук Н.А., Михелькевич В.Н., Рябинова Е.Н.

13.00 .00 - педагогические науки Междисциплинарная интеграция как метод обеспечения высокой интенсивности..

тию данной категории обучающихся в сфере науки, техники, технологий и инновационного развития пока не отражено такое направление поддержки и развития одаренных детей и молодежи, как их продвинутое и ускоренное обучение, успешный педагогический опыт которого имеется в Самарском государственном техническом университете. На основе этого опыта анализируются возможности продвинутого и ускоренного обучения и доказывается, что оно является одним из эффективных способов поддержки и развития одаренной молодежи. На основе имеющегося теоретического и практического опыта отмечается, что технические университеты с их многоуровневыми структурами высшего профессионального образования могут стать весьма действенным интеллектуальным ядром интегрированных систем непрерывного образования, включая в свои организационно-методические структуры различные образовательные учреждения довузовского и дополнительного послевузовского обучения. Описывается опыт создания и функционирования интегрированной образовательной системы непрерывного и дифференцированного (по способностям) образования «Школа - вуз» в гомогенных группах. Показано, что обучение одаренных обучающихся в группах с равными умственными способностями благоприятно влияет на их самооценку и им в такой ситуации приходится учиться с полной отдачей сил, ощущая постоянную стимуляцию со стороны одноклассников. В качестве примера приводятся характеристики потенциала академического колледжа как ассоциированного образовательного учреждения нового типа, функционирующего на основе организационно-методического объединения университета и школы и одновременно являющегося структурным подразделением обоих учредителей. Отмечено, что рассмотренные модели структур интегрированных образовательных систем обладают различной степенью интенсивности обучения, в связи с чем нормирование среднестатистической загрузки обучающихся в академическом колледже приобретает особую значимость и актуальность. Исходя из общепринятой предельно допустимой недельной учебной загрузки молодого человека, обусловленной его психофизиологическими возможностями, социальными условиями и культурными потребностями, описывается методика ее гибкого нормирования, эффективность которого подтверждена многолетним мониторингом выпускников академического колледжа, ставших впоследствии успешными учеными, изобретателями, специалистами.

Ключевые слова: одаренные обучающиеся; интегрированная образовательная система; академический колледж; методика гибкого нормирования; интенсивность обучения.

Одним из приоритетных направлений в работе государственных и областных структур Самарской области является привлечение творчески одаренной молодежи к научно-исследовательской деятельности [1]. В рамках XVIII Международной конференции «Проблемы управления и моделирования в сложных системах» и Совета по вопросам управления и развития Самарской области была представлена и принята Концепция Единой Самарской областной системы мер по выявлению и развитию творчески одаренной молодежи в сфере науки, техники и технологий и инновационному развитию Самарской области [2]. Она была разработана в соответствии с постановлением Губернатора Самарской области от 30.10.2013 г. № 272 «Об образовании Координационного совета по работе с одаренной молодежью в сфере науки и техники при Администрации Губернатора Самарской области» и утверждена 27 января 2016 года. Детально разработанные и утвержденные министерством образования и науки Самарской области программы «Взлет» и «Полет» сопровождения и поддержки развития одаренной молодежи, начиная со средней школы и заканчивая обучением в аспирантуре и докторантуре, предусматривают большое число организационных и психолого-педагогических мероприятий, обеспечивающих их эффективное и устойчивое функционирование.

Вместе с тем, в структуре Единой системы мер по выявлению и развитию творчески одаренной молодежи в сфере науки, техники, технологий и инновационному развитию Самарской области пока не нашло отражение одно из возможных и весьма кардинальных направлений поддержки и развития одаренной молодежи - их продвинутое и ускоренное обучение [3], успешный педагогический опыт которого имеется в Самарском государственном техническом университете (СамГТУ) [4-6]. В 90-е годы $\mathrm{XX}$ столетия в структуре Самарского политехниче- ского института (ныне - СамГТУ) успешно функционировал академический колледж по продвинутому и ускоренному обучению одаренных обучающихся в интегрированной системе непрерывного образования «Школа - вуз» [7-10].

Областной академический колледж Самарского политехнического института (СамПИ) осуществлял свою деятельность в соответствии с «Законом Российской Федерации об образовании», «Положением о высшем учебном заведении Российской Федерации», «Временным положением о средней образовательной школе России», «Временным положением о многоуровневой системе высшего образования Российской Федерации», «Примерным положением о лицее», утвержденном Министерством народного образования Российской Федерации 22.02.1990 г. Его учредителями, наряду с СамПИ, являлись средние общеобразовательные школы и технические лицеи городов: Самара, Тольятти, Отрадный и других населенных пунктов Самарской области в лице Управления образования администрации Самарской области. «Положение об областном академическом колледже Самарского политехнического института» было разработано его научным руководителем - В.Н. Михелькевичем, деканом - Е.Н. Рябиновой, заместителем первого проректора института - В.М. Мегедь и утверждено ректором СамПИ - Ю.П. Самариным и начальником управления образования администрации Самарской области - Е.Я. Коганом [11]. При этом учитывался положительный опыт обучения одаренных детей в школах Великобритании [12; 13], Германии [14], Японии [15] и ряда американских школ, в старших классах которых для творчески одаренных индивидуумов создаются академические группы, осваивающие одновременно с школьными образовательными программами первый, а иногда и второй курс университета [16-18]. После окончания школы такие выпускники зачисляются, соответственно, на 
второй или третий курс университетов, в большинстве своем сотрудничающих со школами по обучению одаренной молодежи, но, вообще говоря, это могут быть любые вузы.

Несмотря на имеющийся положительный опыт и достаточно высокую результативность подобной работы, проблема распределения обучающихся по группам в соответствии с их умственными способностями и продвинутым уровнем подготовки является не решенной до настоящего времени [19]. Почти век исследователи собирают данные об эффективности такого распределения и до сих пор не пришли к единому мнению: одни считают, что формирование отдельных групп для одаренных обучающихся является необходимым условием их успешного обучения; другие объявляют этот метод недемократичным и нерациональным.

Еще в 20-е годы XX столетия психолог В.М. Экземплярский [20] - сторонник специальных школ для одаренных обучающихся - систематизировал различные мнения «за» и «против» создания таких школ. Доводы, приводимые в пользу обучения в специализированных классах для одаренных обучающихся, сводятся к следующему:

- продвижение в обучении возможно со свойственной для обучающегося скоростью;

- инициирование стабильного интереса к познавательной деятельности у обучающихся и их регулярное сотрудничество с одноклассниками;

- использование учебных материалов и образовательных технологий, соответствующих познавательным потребностям и умственному уровню обучающихся в силу однородного состава класса.

Аргументы «против» повторяются с удивительным постоянством:

- выделение одаренных обучающихся неблагоприятно отразится на их эмоционально-волевой сфере, вызывая у них высокомерие и развитие чрезмерного самомнения;

- обучающиеся в обычных школах будут лишены положительных примеров, стимулов к усиленной работе, имея в качестве образца учебную деятельность и поведение успешных индивидуумов.

Следствием этих доводов считают неблагоприятный социально-культурный результат - общее понижение культурного уровня массовых школ; создание «элиты», «аристократии духа», лишенной интереса и понимания обычных людей. А поскольку жизнь взрослых проходит во взаимодействии с людьми разного уровня способностей, то необходимо с детских лет приучаться к этому.

В нашей стране с 60-х - 70-х годов XX века существуют специализированные классы и школы, обучение в которых ведется по специально разработанным программам по определенным учебным дисциплинам. Результаты показывают, что в целом успехи обучающихся и выпускников таких учебных заведений гораздо выше результатов их сверстников из обычных классов [21-23]. Замечено также, что положительное влияние обучения на академические успехи обучающихся в однородных по степени одаренности группах оказывается только в случае использования специально разработанных программ. Исследования также показали, что обучение одаренных обучающихся в группах с равным умственным уровнем благоприятно влияет на их самооценку: в такой ситуации приходится учиться с полной отдачей сил, ощущая постоянную стимуляцию со стороны одноклассников. При обучении одаренных учащихся в обычных классах часто создается ситуация высокомерного отношения к сверстникам, не понимающим азбучных истин, что формирует завышенную самооценку.

Другой «стороной медали» обучения одаренного обучающегося в обычном классе является его отказ от личного интереса к познавательной деятельности и «сползание» к уровню «середнячка». Имеются данные и для одаренных подростков, испытывающих дискомфорт среди равных себе: это связано с созданием собственных нервных перегрузок для подтверждения своей исключительности в ситуациях постоянного интеллектуального соревнования. В таких случаях требуется психологическая поддержка по правильной корректировке Я-концепции. Очевидно, что эта дискуссионная проблема должна решаться с учетом конкретных социально-психологических обстоятельств. Одаренность настолько индивидуальна и неповторима, что вопрос об оптимальных условиях обучения каждого индивидуума должен рассматриваться персонально.

Академический колледж (АК) - образовательная система элитарного типа для продвинутого и ускоренного обучения одаренных учащихся - был образован в структуре СамПИ (СамГТУ) в 1991 году. Свое название «колледж» он получил по типу учебного подразделения университета, в котором ведется подготовка специалистов 1-го квалификационного уровня. В целом, интегрированная образовательная система (ИОС) «технический лицей - младший колледж технического вуза» является одной из разновидностей систем непрерывного образования типа «школа - вуз». Замена термина «младший колледж» технического вуза на «академический колледж» технического вуза не является результатом погони за престижным словом, а несет смысловую и методологическую нагрузку. Эта терминологическая деталь подчеркивает нацеленность студентов АК на продолжение образования в исследовательских и профессиональных вузах по общеобразовательным, академическим программам.

Первоначально АК создавался на базе технического лицея - школы № 51 Автозаводского района города Тольятти в интересах целевой индивидуальной подготовки научных работников и технических специалистов высшей квалификации для конструкторских служб и производства Волжского автомобильного завода из числа наиболее талантливых и преуспевающих учащихся.

Первый опыт создания и функционирования интегрированной системы непрерывного и дифференцированного (по способностям) образования «Школа - вуз» в гомогенных группах приобретался при отработке структуры так называемого одногодичного АК. Методологическим ядром концепции одногодичного АК является совмещение по времени и интеграция по содержанию образовательной программы 11-го класса средней общеобразовательной школы (лицея, гимназии) и образовательно-профессиональной программы 1-го курса технического университета (по конкретному предметному направлению). 
Возможность такой интеграции во многом была предопределена переходом СамГТУ на многоуровневую систему высшего технического образования. Реализуемый при этом принцип прямой фундаментализации знаний в подготовке бакалавров предусматривает преподавание на 1-м уровне дисциплин гуманитарного и естественно-научного циклов. При этом подавляющее большинство дисциплин выпускного класса средней школы и 1-го курса университета совпадают как по наименованию, так и по содержанию. Именно это обстоятельство позволяет интегрировать одноименные учебные дисциплины, строить их единые структурно-логические схемы, перейти от индуктивных методов изложения материала к дедуктивным, исключить его дублирование и тем самым существенно повысить интенсивность обучения [4-6].

Большой интерес к созданию и функционированию новой образовательной системы АК проявили не только старшеклассники и их родители, но и педагогическая общественность школ области и вузов России, директора школ и работники органов управления образования всех уровней. И это не случайно, так как в этой системе был сконцентрирован целый спектр социальных, дидактических, профориентационных и других общественно значимых проблем.

АК - это ассоциированное образовательное учреждение нового типа, функционирующее на основе организационно-методического объединения университета и школы и одновременно являющееся структурным подразделением обоих учредителей.

Основные преимущества образовательной системы АК заключаются в следующем:

- система ориентирована и на поиск, поддержку и развитие талантливых и одаренных детей, и на их специфическое обучение и воспитание, и на подго- товку из их числа будущей интеллектуальной элиты общества;

- система направлена на пропедевтическую научно обоснованную и более глубокую профориентационную деятельность вузов в средних школах, на эффективный поиск подходящего по личностным и профессиональным наклонностям абитуриента;

- система стимулирует академическую активность и динамизм интеллектуального и творческого развития учащихся, обеспечивая продвинутость и сокращение срока обучения минимум на один год для достижения желаемого уровня образования, общение с наиболее квалифицированными школьными, вузовскими педагогами и учеными, более высокий уровень социальной защищенности и конкурентоспособности на рынке интеллектуального труда.

По мере возрастания интереса к новой образовательной системе увеличилось число школ г. Самары и Самарской области, на базе которых были организованы отделения АК, причем наряду с одногодичными стали функционировать двух- и трехгодичные АК, селективный прием в которые производился из числа выпускников 8-х и 9-х классов соответственно. В двухгодичном АК обучающиеся осваивают образовательные программы 10-го и 11-го классов средней школы и 1-го курса университета за два учебных года, в трехгодичном АК - образовательные программы 9-го, 10-го и 11-го классов средней школы и 1-го курса университета за три учебных года. Реализация различных моделей организации ИОС зависит от степени интеграции образовательных (школьных) и образовательно-профессиональных (вузовских) программ. Структура интегрированной системы непрерывного образования «Школа - вуз» для продвинутого и ускоренного обучения одарённых обучающихся приведена на рис. 1.
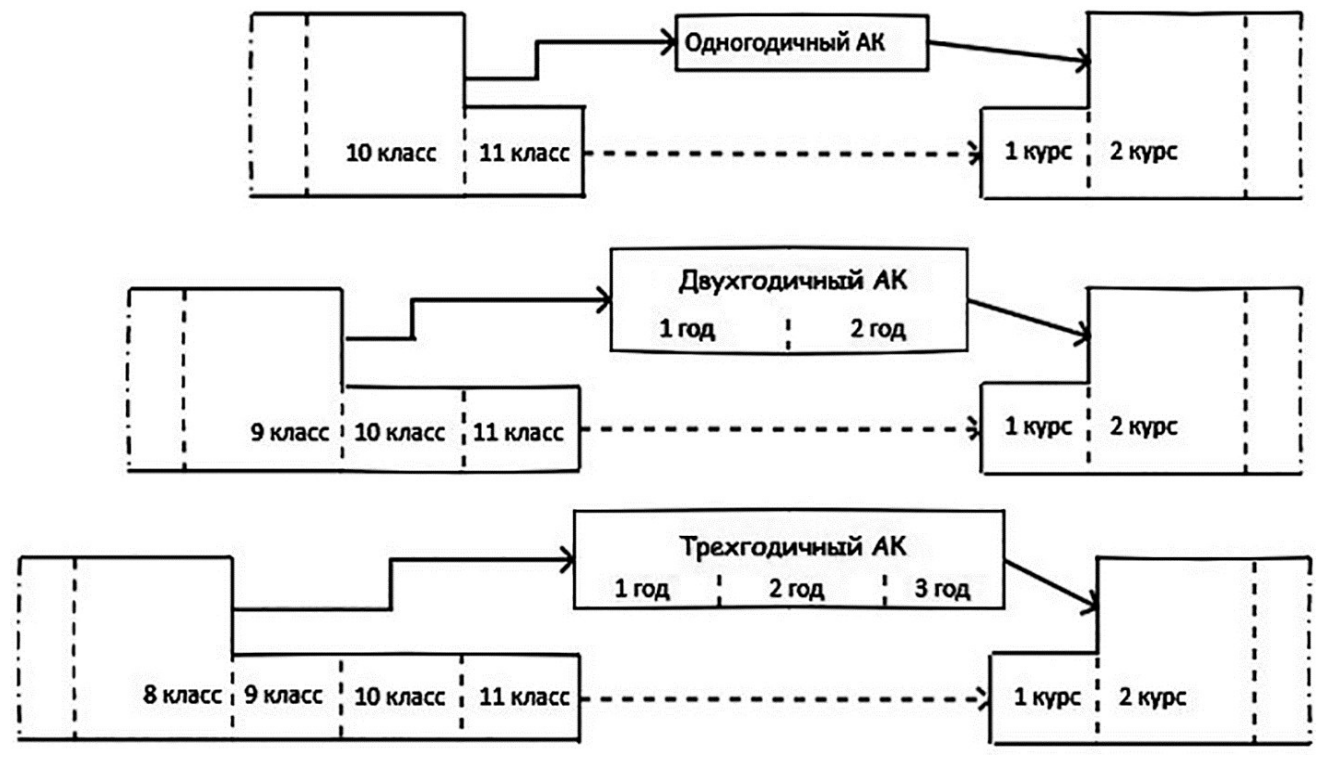

Рисунок 1 - Структура интегрированной системы непрерывного образования «Школа - вуз» для продвинутого и ускоренного обучения одаренных обучающихся

Жесткий конкурсный отбор при зачислении в АК, включающий в себя психодиагностические исследования индивидуальных качеств абитуриентов [11] и тестовые испытания по профильным предметам, позволяет объективно выявить одаренных детей и подростков и их возможности обучаться по интегрированным программам одно-, двух- или трехгодич- ных АК. Одаренные дети осваивают учебный материал намного быстрее, чем среднестатистические школьники [18-23]. Однако следует избегать перегрузок обучающихся учебной работой в условиях повышенной интенсивности познавательной деятельности. Это обеспечивается за счет следующих факторов: 
- использование интенсивных, в том числе компьютерных технологий обучения;

- применение интегрированных монодисциплинарных и трансдисциплинарных курсов;

- привлечение к работе в АК талантливых школьных учителей и вузовских педагогов.

Очевидно, что перечисленные выше модели структур ИОС обладают различной степенью интенсивности обучения. В связи с этим нормирование среднестатистической загрузки обучающихся в АК приобретает особую значимость и актуальность. Рассмотрим методику гибкого нормирования учебной нагрузки студентов одногодичного АК, исходя из общепринятой предельно допустимой (54-часовой: 6 часов аудиторных занятий и 3 часа самостоятельной работы) недельной загрузки молодого человека, обусловленной его психофизиологическими возможностями, социальными условиями и культурными потребностями. В самом общем виде она представляет собой сложную многокритериальную оптимизационную задачу. При этом дисциплины, включенные в учебные планы 11-го класса средней школы и 1-го курса университета разделим на следующие подгруппы:

1. Дисциплины школьной (ш) и вузовской (в) программ, не подлежащих интеграции в силу их эксклюзивности и преподаваемых по типовым программам и технологиям обучения с трудоемкостью обучения (в часах) Дш и Ді.

2. Неинтегрируемые школьные и вузовские дисциплины, обучение по которым проводится с использованием интенсивных педагогических технологий (концентрированного обучения, компетентностно-модульного, методов проектов, конкретных ситуаций и т.д.), с трудоемкостью их освоения (в часах) Да и Д2.

3. Дисциплины монодисциплинарной интеграции: они разрабатываются на основе объединения и взаимной интеграции содержания двух одноименных дисциплин школьного и вузовского учебных планов (математика, физика, химия, физическая культура и т.д.) и имеют единую систему структурно-логических связей интегрированного в ней учебного материала Дш и Д. $_{3}^{\mathrm{E}}$.

4. Дисциплины трансдисциплинарной интеграции: они разрабатываются на основе объединения и взаимной интеграции содержания различных дисциплин учебного плана ИОС (например, математика и иностранный язык, математика и физика, черчение и компьютерная графика, культурология и иностранный язык и т.д.) и имеют единую систему структурно-логических связей излагаемого в ней учебного материала Д 4 и $Д_{4}^{\mathrm{B}}$.

Интенсивность использования приемов междисциплинарной интеграции и высоких технологий обучения будем оценивать через коэффициенты снижения трудоемкости освоения соответствующей дисциплины:

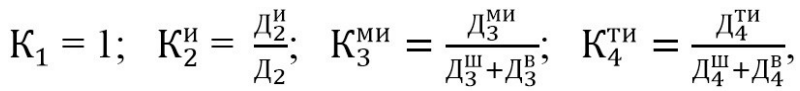
где: Ди - время (в часах), необходимое на освоение дисциплины по интенсивной технологии; Диㅡㄹ - время (в часах), необходимое на освоение монодисциплинарной интегрированной дисциплины; Д мя (в часах), необходимое на освоение трансдисциплинарной интегрированной дисциплины.
В приведенных выражениях речь идет о среднестатистических, эмпирически установленных объемах времени. При этом отметим, что из многочисленных публикаций известно, что численные значения коэффициентов снижения трудоемкости освоения учебного материала за счет использования интенсивных технологий обучения, монодисциплинарной и трансдисциплинарной интеграции находятся в диапазонах:

$\mathrm{K}_{2}^{\mathrm{и}}=0,66 \div 0,75 ; \mathrm{K}_{3}^{\mathrm{ми}}=0,5 \div 0,6 ; \mathrm{K}_{4}^{\mathrm{Tи}}=0,66 \div 0,8$.

При принятых обозначениях планируемая недельная нагрузка студента АК, обозначенная буквой П, численно определяется выражением:

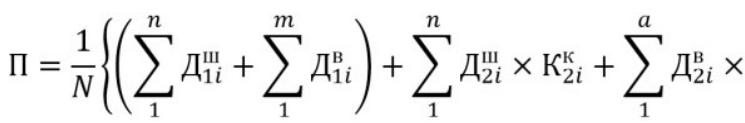

$$
\begin{aligned}
& \left.\times \mathrm{K}_{2 i}^{\mathrm{U}}+\sum_{1}^{b}\left(Д_{3 i}^{\mathrm{m}}+Д_{3 i}^{\mathrm{B}}\right) \times \mathrm{K}_{3 i}^{\mathrm{Mu}}+\sum_{1}^{c}\left(Д_{4 i}^{\mathrm{m}}+Д_{4 i}^{\mathrm{B}}\right) \times \mathrm{K}_{4 i}^{\mathrm{Tu}}\right\} \leq H,
\end{aligned}
$$

где: $\mathrm{N}$ - число недель за период изучения рассматриваемых курсов; $\mathrm{H} \leq 54$.

Нормирование среднестатистической загрузки студентов АК ИОС в условиях существенного возрастания интенсивности обучения становится эффективным инструментом и основным методом предотвращения перегрузок в обучении. При этом сам процесс нормирования приобретает новое свойство - он становится гибким, так как оперативно (во времени) учитывает и оценивает большое число вариативно изменяющихся факторов. Суть гибкого нормирования состоит в учете следующих быстро изменяющихся или целенаправленно и совместно организуемых школой и вузом факторов:

- в выявлении возможностей школы и вуза преподавать в планируемом учебном году интегрированные (монодисциплинарные и трансдисциплинарные) курсы;

- в количественном учете глубины и интенсивности интеграции обязательных дисциплин учебных планов школы и вуза;

- в установлении возможностей применения интенсивных (компьютерных и нетрадиционных) технологий обучения при преподавании конкретных дисциплин и в выявлении количественных оценок эффектов «сжатия» информации по каждой из таких дисциплин;

- в оценке состояния и уровня «продвинутости» учебных курсов.

Многоуровневые структуры высшего технического образования обладают рядом неоспоримых преимуществ по сравнению с традиционными многоуровневыми системами высшего профессионального образования. Главными из этих преимуществ являются следующие:

- обеспечение гибкости организации и быстрой перестройки учебного процесса;

- создание благоприятных условий для интеграции научных знаний;

- обеспечение более высокого уровня фундаментальной естественнонаучной и общетехнической подготовки; 
Тимощук Н.А., Михелькевич В.Н., Рябинова Е.Н.

- ориентация на более высокий уровень общекультурной, гуманитарной и социально-экономической подготовки своих выпускников;

- обеспечение учащимся и студентам большей свободы выбора своего образовательного маршрута с учетом уровня и динамики развития способностей, наклонностей и интересов;

- приспособленность к эффективному функционированию в обществе с рыночной экономикой и быстрое реагирование на конъюнктуру рынка труда;

- возможность создания в своих структурах интегрированных систем непрерывного образования.

Многолетний мониторинг выпускников АК ИОС показал эффективность охарактеризованной нами образовательной системы. Они пополнили ряды ученых, талантливых изобретателей и специалистов, чья деятельность способствует могуществу страны. В национальных интересах - максимально развивать способности одаренных обучающихся и начинать этот процесс следует как можно раньше.

Технические университеты с многоуровневыми структурами высшего технического образования могут стать интеллектуальным ядром интегрированных систем непрерывного образования, включая в организационно-методические структуры различные образовательные учреждения довузовского и дополнительного послевузовского обучения. Опыт образовательных учреждений Самарской области по созданию и функционированию интегрированных систем непрерывного образования самых разнообразных типов убедительно подтверждает их целесообразность и эффективность.

\section{СПИСОК ЛИТЕРАТУРЫ:}

1. Овчинников Д.Е., Загребова Л.Е., Бальзанников М.И., Пиявский С.А., Акопов Г.А., Смирнов С.В., Шаталов Р.Б., Глушков А.А. Концепция развития творческого потенциала Самарской области // Проблемы управления и развития Самарской области: тр. науч.-практ. конф. Самара: АНО «Совет по вопросам управления и развития Самарской области», ООО «ОФОРТ», 2016. С. 36-44.

2. Проблемы управления и развития Самарской области: тр. науч.-практ. конф. (20-25 сентября 2016 г. Самара) / под общ. ред. В.А. Виттиха. Самара: АНО «Совет по вопросам управления и развития Самарской области», ООО «ОФОРТ», 2016. 120 с.

3. Тимощук Н.А., Михелькевич В.Н., Рябинова Е.Н. Обучение одаренной молодежи в интегрированной образовательной системе // Актуальные проблемы гуманитарных и социально-экономических наук: сб. мат-лов XI междунар. науч.-практ. конф. «Актуальные проблемы психологии и педагогики». В 2 кн. М.: Изд-во «Перо»; Вольск: Тип. ВВИМО, 2017. Кн. 2. С. 89-94.

4. Михелькевич В.Н., Рябинова Е.Н. Концепция и организационно-методические основы интегрированной образовательной системы «технический лицей младший колледж технического вуза». Отчёт из 2 частей. Самара: СамПИ, 1992. Ч. 1. 41 с.; Ч. 2.31 с.

5. Михелькевич В.Н., Третьяков В.С., Беднова Л.Н. Интегрированная образовательная система «технический лицей - младший колледж» для одаренных детей // Компетентность и ответственность: тез. докладов III Европейской конф. Мюнхен, 1992. С. 101.
6. Беднова Л.Н., Михелькевич В.Н., Рябинова Е.Н. Концепция и опыт интегрированной образовательной системы «технический лицей - младший колледж технического вуза» // Тез. докл. науч.-практ. конф. Пермь: ППИ, 1992. С. 84-85.

7. Евдокимов М.А., Рябинова Е.Н. Опыт работы академического колледжа // Актуальные проблемы университетского технического образования: тез. докл. науч.-метод. конф. 27 января 1999 г. Самара: СамГТУ, 1999. С. 210.

8. Мегедь В.М., Михелькевич В.Н., Рябинова Е.Н. Академический колледж - образовательная система для целевой подготовки специалистов // Целевая индивидуальная подготовка специалистов в условиях рыночной экономики. СПб., 1992. С. 84-85.

9. Михелькевич В.Н., Рябинова Е.Н., Петрованова Л.М. Психологическое сопровождение продвинутого и ускоренного обучения одаренных учащихся // Психологическая поддержка в развитии творческой одаренной личности. Челябинск: ЧГТУ, 1993. С. 1516.

10. Рябинова Е.Н. Интегрированные образовательные системы «средняя школа - вуз» // Двухступенчатое образование и самофинансирование вузов. Балтик Легис интернешнл. Латвия, Юрмала, 1992. C. $53-54$.

11. Положение об областном академическом колледже Самарского государственного технического университета / разработчики: В.Н. Михелькевич, Е.Н. Рябинова, В.М. Мегедь. Самара: Управление образования администрации Самарской области, 1992. 9 с.

12. Цейкович К.Н. Система образования в Великобритании. Проблемы зарубежной высшей школы: обзорн. инф. НИИ ВШ. Вып. 2, 1989. 64 с.

13. Сергеева Н.И. Обучение одарённых детей в школах Великобритании // Советская педагогика. 1990. № 6. С. 137-144.

14. Ворожейкина О.Л. Система образования в ФРГ. Проблемы зарубежной высшей школы: обзорн. инф. НИИ ВШ. Вып. 1, 1991. 132 с.

15. Галаган А.И. Система образования в Японии. Проблемы зарубежной высшей школы: обзорн. инф. НИИ ВШ. Вып. 1, 1989. 60 с.

16. Малькова 3.А. Современная высшая школа США. М.: Педагогика, 1971. 368 с.

17. Тартарашвили Т.А. Система подготовки интеллектуальной элиты в США / Под науч. ред. Ю.А. Клехо. М., 1988. 68 с.

18. Одаренные дети: Пер. с англ. / общ. ред. Б.М. Бурменской $\quad$ и В.М. Слуцкого. М.: Прогpecc, $1991.376 \mathrm{c}$.

19. Доровский А.И. Дидактические основы развития одаренных учащихся: учебное пособие. М.: Российское педагогическое агенство,1998. 210 с.

20. Экземплярский В.М. Проблемы школ для одаренных. М.-Л., 1927. 82 с.

21. Рабочая концепция одаренности / науч. ред. В.Д. Шадриков. М.: Магистр, 1998. 68 с.

22. Возможные миры или создание практики творческого мышления: пособие для преподавателей / В.С. Бонмов, А.В. Лаптева, С.В. Ермаков и др. М.: Интерпракс, 1994. 128 с.

23. Рабочая концепция одаренности / под ред. Д.Б. Богоявленской. Самара: Президентская программа «Дети России», 2000. 41 с. 


\title{
CROSS-DISCIPLINARY INTEGRATION AS A HIGH INTENSITY METHOD OF GIFTED STUDENTS' TRAINING
}

(C) 2017

\author{
Timoschuk Nina Alexandrovna, candidate of philological sciences, associate professor, \\ head of Psychology and Pedagogy Department \\ Mikhelkevich Valentin Nicolaevich, doctor of technical sciences, \\ professor of Psychology and Pedagogy Department \\ Ryabinova Elena Nicolaevna, doctor of pedagogical sciences, \\ professor of Higher Mathematics and Application-Oriented Informatics Department \\ Samara State Technical University (Samara, Russian Federation)
}

\begin{abstract}
The paper contains successful pedagogical experience of Samara State Technical University in the field of exceptional children's advanced and accelerated training. On the basis of this experience possibilities of the advanced and accelerated training are analyzed. This kind of training is considered to be one of the most effective ways of gifted youth's development. On the basis of the available theoretical and practical experience the authors note that technical universities with their multilevel structures of higher education can become very effective intellectual centers of the integrated systems of continuous education, including various educational institutions of pre-university and additional postgraduate training. The paper contains experience of an integrated educational system of continuous and differentiated (on abilities) education «School - HEI» in homogeneous groups. It is shown that training of gifted students in groups with equal mental capacities favorably influences their self-assessment and they in such situation should study wholeheartedly forces, feeling continuous stimulation from schoolmates. Characteristics of capacity of the academic college as the associated educational institution of the new type functioning on the basis of organizational and methodical merging of the university and school and at the same time being structural division of both founders are given as an example. It is noted that the considered models of structures of the integrated educational systems possess various degree of intensity of training, in communication with what rationing of average loading of students in the academic college acquires the special importance and relevance. Proceeding from the standard maximum permissible week educational loading of the young man caused by his psychophysiological opportunities, social conditions and cultural requirements the technique of her flexible rationing which efficiency is confirmed with long-term monitoring of the graduates of the academic college who have become subsequently successful scientists, inventors, experts is described.
\end{abstract}

Keywords: gifted students; integrated educational system; academic college; flexible standardization methodology; intensity of training.

УДК 37.07

\section{СОДЕРЖАТЕЛЬНЫЕ АСПЕКТЫ РАЗРАБОТКИ СТРАТЕГИЙ И ПРОЕКТОВ МУНИЦИПАЛЬНЫХ ОРГАНОВ УПРАВЛЕНИЯ ОБРАЗОВАНИЕМ}

(C) 2017

Фишман Лев Исаакович, доктор экономических наук, доктор педагогических наук, профессор, декан факультета экономики, управления и сервиса

Иванов Михаил Юрьевич, доктор экономических наук, доцент, заведующий кафедрой экономики Самарский государственный сочиально-педагогический университет (2. Самара, Российская Федераџия)

Аннотация. В данной статье представлены теоретические подходы к разработке стратегий и проектов муниципальных органов управления образованием. Рассмотрение муниципальной системы образования как территориально-отраслевой комплекса, структурно изоморфного холдингу, позволило определить институциональную роль муниципального органа управления образованием как аналог управляющей компании холдинга, а учреждения и организации, непосредственно оказывающие образовательные услуги, как производственные подразделения холдинга. Выявление специфики связей муниципального органа управления (управляющей подсистемы) и непосредственных производителей образовательных услуг (управляющей подсистемы) позволило выявить функции муниципального органа управления образованием, который ставит задачи перед производителями образовательных услуг, входящими в территориально-отраслевой комплекс, и обеспечивает реализацию этих задач соответствующими ресурсами. Построена классификация ресурсов, которые являются объектами управления головной организации территориально-отраслевого комплекса: организационные ресурсы, финансовые ресурсы, кадровые ресурсы, ресурс формирования общественного мнения, информационный ресурс. На основе данной классификации сгруппированы механизмы управления по признаку однородности объектов управления: механизмы оптимизации структуры сети организацийпроизводителей услуг, механизмы финансирования организаций-производителей услуг, механизмы работы с кадрами организаций-производителей услуг, механизмы взаимодействия организаций-производителей услуг с субъектами внешней среды, механизмы контроля функционирования и мониторинга в муниципальной системе образования. При этом задачи муниципальных стратегий, конкретные цели муниципальных проектов должны быть связаны с модернизацией данных механизмов. 